\title{
Competitive Activity of Cadets in Army Hand-to-Hand Fighting
}

\author{
Kuznetsova Z.M. \\ Chaykovskiy State Institute of Physical Culture \\ Chaykovskiy, Russia \\ kzm_diss@mail.ru
}

\author{
Garanin E.A. \\ Tyumen Higher Military- Engineering Command \\ School (military Institute) \\ Tyumen, Russia \\ evgeni.garanin@yandex.ru
}

\begin{abstract}
The article is about the main tendencies of competitive activity development among cadets. Army hand-to-hand fighting nowadays is the most popular kind of sport among pre-induction age people, cadets of military higher educational establishment. Army hand-to-hand fighting federation considers all factors, directed toward this kind of sport development, as the alternative of different segments of population motor activity increase. During the comparative analysis of the past and present army hand-to-hand fighting competitive activity the authors define the increasing tempo of contemporary army hand-to-hand fighting development.

The main feature, that characterizes competitive activity of military higher educational establishment cadets, is the visual appeal of this kind of sport improvement at all levels of its development.
\end{abstract}

Keywords-competitive activity; army hand-to-hand fighting; cadets; technical actions; ratio.

\section{INTRODUCTION}

Contemporary army hand-to-hand fighting presents a universal system of general and special physical training. Army hand-to-hand fighting includes the elements and techniques of attack and defense. It combines a lot of functional elements from the great arsenal of world single combats kinds. All attack and defense techniques of army hand-to-hand fighting are widely used in real fighting activity, especially in training military men. It is also successfully introduced into educational program of military men and became the base for their physical training in all military structures of the Russian Federation.

In this connection there appeared a scientific and practical interest in the problem of competitive activity effectiveness increase among cadets, who go in for army hand-to-hand fighting.

An effective structure of any athletes' competitive activity in kinds of sport is conditioned by the objective and means of sports training.

In army hand-to-hand fighting for military school cadets there are two directions of training: sports and professionapplied training.

Scientific literature analysis showed that power kinds of sport use during physical training of cadets provides an effective profession-applied physical training. Below the opinions of some specialists are presented.

Eliseev S.A., (2017) considers that profession-applied physical training development among cadets of military schools has always been interesting for the specialists in this sphere. In this connection he pays attention to physical training of border forces cadets.

Labeshchenkov O.V. (2018) studies sports-technical mastery formation and development engineering profile military-educational establishments in cadets of airborne training.

Grankin N.A. (2012) pays great attention to power kinds of sport use in military men physical training.

Zhuzhgov A.I. (2017) in his research works pays attention to the necessity of power kinds of sport for military higher educational establishment cadets, as the base for psychological adaptation of military-applied physical readiness formation among cadets to the future military profession.

S.A. Pauesov (2017) studied physical working capacity of cadets in extreme conditions of combat missions realization, conditioning the necessity to increase the effectiveness of cadets' functional training using the exercises for endurance.

Solonitsin R.A. (2011) studies the questions of special motor skills for shooting development.

Al.V. Glazistov, A.S. Kuznetsov (2005) actualize basic technical training organization in sports hand-to-hand fighting at the initial stage of a long-term technical-tactical training as the base for athletes' successful competitive activity.

Glazistov Al.V. (2007, 2008) considers technical-tactical analysis of competitive activity the base of the effective technical-tactical readiness increase in hand-to-hand fighting.

M.V. Nikityuk (2004) pays attention to functional training of students-cadets, who go in for Greco-Roman wrestling, as the base for a successful competitive activity.

\section{MATERIALS AND METHODS}

The article considers the main tendencies of studentscadets competitive activity. Method of scientific literature analysis and generalization and method of mathematical statistics are used in the research. 
It should be noted that differently oriented competitive activity study in army hand-to-hand fighting helps to reveal the factors, which define the effectiveness of the performances. First of all, it is physical and functional training, technical-tactical training, psychological training, if hand-to-hand fighting athletes fulfill the definite technicaltactical actions. In army hand-to-hand fighting, first of all, such level of sports-technical mastery achievement happens owing to legs, hands motor actions in a throw increase.

\section{RESULTS}

Cadets' competitive activity study helps to get subjective information about the abilities and the degree of readiness realization in terms of competitive combat.

The main characteristic of competitive activity in army hand-to-hand fighting is a great arsenal of techniques and motor movements on a wrestling mat fulfillment. In this connection it is very important to estimate technical-tactical actions of cadets, considering a combat the base for combat activity.

For cadets' competitive activity estimation the authors held the following actions registration: the number of effective hands blows and kicks; the number of effective throws; general number of points for one combat.

TABLE I presents summarized volume of cadets techniques during different level competitions.

TABLE I. SUMMARIZED VOLUME OF CADETS' TECHNICALTACTICAL ACTIONS DURING THE COMPETITIONS

\begin{tabular}{|l|c|c|c|c|}
\hline \multirow{2}{*}{$\begin{array}{c}\text { Level of } \\
\text { competitions }\end{array}$} & \multicolumn{4}{|c|}{ Technical level indices of cadets } \\
\cline { 2 - 5 } & $\begin{array}{c}\text { Hands } \\
\text { blows, } \\
\text { points }\end{array}$ & $\begin{array}{c}\text { Kicks, } \\
\text { points }\end{array}$ & $\begin{array}{c}\text { Throws, } \\
\text { points }\end{array}$ & $\begin{array}{c}\text { Total number } \\
\text { of points }\end{array}$ \\
\hline $\begin{array}{c}\text { Friendly } \\
\text { combats }\end{array}$ & $6,42 \pm 0,53$ & $8,01 \pm 0,68$ & $6,52 \pm 0,81$ & $20,95 \pm 2,13$ \\
\hline $\begin{array}{c}\text { Official } \\
\text { competitions }\end{array}$ & $8,21 \pm 0,45$ & $9,11 \pm 0,60$ & $7,01 \pm 0,62$ & $24,33 \pm 1,22$ \\
\hline
\end{tabular}

Cadets' combatant activity and competitive activity effectiveness depend on the level of competitions, their readiness, which is proved by the research results.

TABLE I shows that cadets' fulfilled actions change is typical for all components of competitive activity such as hands blows and kicks, throws and total number of points. Official starts influence more wrestlers' realization. In such kind of starts they have higher results in combat conduct technicality.

The volume of individual technical actions fulfilled by cadets-wrestlers depends on their experience of combat conduct and readiness. Among the most important technical actions are the kicks and hands blows in the official starts had $8,21 \pm 0,45$ и $9,11 \pm 0,60$ points. In friendly combats these indices were lower as cadets-wrestlers realized themselves not fully.
Mentioned above tendencies in changing the effectiveness of technical actions during the competitions of different level, in general, are typical for all cadets-wrestlers. However, we can't ignore several typical features of cadets' technical readiness. First of all, it is army hand-to-hand fighting importance for each wrestler. Secondly, motivation is expressed in cadets' technical actions special weight increase with each competition.

Activity indices of cadets-wrestlers also depends on their physical, functional and psychological readiness.

Cadets with relatively high level of physical and functional readiness had higher level and quality of technical actions, than cadets, who go in for hand-to-hand fighting during training lessons. In case of systematic trainings technical and tactical mastery of cadets-wrestlers improves and on this basis the effectiveness and activity of technical actions fulfillment during competitions also improves.

Thus, the component of cadets-wrestlers competitive activity is the level of their technical and tactical mastery and also all technical elements use during the competitions.

Specific weight of the kicks and hand blows leads to combat activity increase. Total volume of combat actions increase leads to the wrestler's professional mastery increase. It should be noted that a timely control and estimation of technical actions development helps to increase their special weight during the competitions. In this connection combat becomes varied, spectacular and effective. Kicks and hands blows, throws become more diverse. The styles of sports combat also change.

Practical recommendations can become the information about the fact that kicks in case of specific weight within one start $64 \%$, can become effective during $47 \%$. Hands blows in case of specific weight $56 \%$, effective can become during $34 \%$. The number of kicks and hands blows in this case would increase, the speed of combat also would increase. The main tendency of competitive activity change among cadetswrestlers can be considered the increase of the specific weight of each technical action during the combat. The volume of kicks and hands blows increase leads to their effectiveness increase. Moreover, it can be noted that the effectiveness of each technical action leads to difference in the effectiveness of fulfillment and the amount of fulfillment. In this connection, there appear different ways of combat conduct.

\section{CONCLUSION}

The held analysis helped to reveal the definite changes in combat of cadets owing to specific weight of structural components of competitive activity change. It can be continued from stage to stage of training. At the same time, specific weight of the throws fulfillment preserves at one level, varies not much and changes within the range till $3 \%$ from the total number of attacks.

Thus, we see the ratio redistribution of wrestlers' technical actions depending on the level and importance of competitions. But the tendency should be one increase of an effective and qualitative technical actions fulfillment during one combat as the base of competitive activity effectiveness. 
"Actual problems of theory and practice physical culture, sport and tourism”. Kazan: Povolzhskaya SAPCST. 2017, vol. 2, pp. 432-434.

[7] Zhuzhgov A.I. Psychological adaptation as the factor of military-applied physical readiness formation among cadets for the future military profession. News of Tula State University. Physical culture. Sport. 2017, vol. 1, pp. 29-35.

[1] Glazistov Al.V., Kuznetsov A.S. Urgency of the basic technical readiness organization in sports hand-to-hand fighting at the initial stage of a longterm technical-tactical training. Student. Intelligence. Future: materials of interuniversity youth conference, dedicated to the $25^{\text {th }}$ anniversary of KamPI. Naberezhnye Chelny: KamPI publishing house. 2005, pp. $79-$ 83.

[2] Glazistov Al.V., Kuznetsov A.S. Technical-tactical analysis of competitive activity among 12-14 year-old boys in hand-to-hand fighting combats. Physical culture: education, formation, training. 2007, vol. 2, pp. 46-50.

[3] Glazistov Al.V., Kuznetsov A.S. The effectiveness of the basic technicaltactical training increase among 10-12 year-old athletes in sports hand-tohand fighting. Sport science bulletin. 2008, vol. 1, pp. $28-31$.

[4] Grankin N. A. Methodology of physical readiness among military men (exercises with dumbbells fulfillment), offered in a new manual (NFP2009). Collection of scientific-methodical articles, NVVIKU, Kstovo. 2012, pp. 65-70.

[5] Eliseev S.A. The process of profession-applied physical training development among cadets of military schools. Scientific conference bulletin. Science, education, society: materials of the International scientific-practical conference. Tambov: Yukom. 2017, vol. 1-4(17), part 4, pp. 76-78.

[6] Eliseev S.A., Konovalov I.E. Potentialitiesanalysis of profession-applied physical training development among cadets of military educational establishments. Materials of the Vth All-Russian scientific-practical conference of young scientists, post-graduates, masters and students
[8] Labeshchenkov O. V. Theoretical aspects of sports-technical mastery formation among cadets of military-educational establishments of engineering profile in terms of airborne training. The International scientific-practical conference "The potential value of education in formation of personality: methodology and application basis" (October, 19-20, 2018, Orenburg)

[9] Nikityuk M. V. Functional training of students-cadets, who go in for Greco-Roman wrestling. Modern problems and prospects of development of physical culture, sports, tourism and social and cultural services: materials of the IInd All-Russian scientific-practical conference. Naberezhnye Chelny: Naberezhnye Chelny branch of Povolzhskaya State Academy of Physical Culture, Sport and Tourism. 2014, pp. 185-186.

[10] Garanin E.A. Physical training of army hand-to-hand fighting combatants taking into account individual style of sports combat conduct. Pedagogico-pshycological and medico-biological problems of physical culture and sport. 2015, vol. 10(1), pp. 29-37. DOI: 10.14526/01_1111_26

[11] Solonitsin R.A. The research results of the ability to increase the accuracy of shooting by means of special motor abilities development. Pedagogico-pshycological and medico-biological problems of physical culture and sport. 2011, vol. 3(20), pp. 114-120. URL: http://www.kamgifk.ru/magazin/journal.htm. 